\title{
Fatal haemorrhage due to a fish bone in the oesophagus; a case report
}

Chathura Nandasiri, Prasadini Senerath, Rohan Ruwanpura

Teaching Hospital Karapitiya, Galle, Sri Lanka

Correspondence:Dr.R.Ruwanpura (rohanr@sltnet.lk)

\section{Introduction}

Foreign bodies in the upper aero-digestive tract are a common problem. Rupture of the oesophagus is one of the rare yet more dramatic conditions and is an emergency. Studies show that $10 \%$ to $20 \%$ of foreign body ingestion in the gastrointestinal tract requires endoscopic treatment and its retention in the esophagus may represent risk of severe complications, with rare fatalities. In addition to endoscopic treatment, surgical procedure might be necessary in approximately $1 \%(1)$.

\section{Case Report}

A 56-year old male was admitted to a surgical ward with a three day history of odynophagia. He had no dysphagia or haematemesis during the admission. There was no history of ingestion of a foreign body. The initial upper gastrointestinal endoscopy and chest radiograph did not reveal any significant changes and the patient was discharged. A week later, he was readmitted due to an episode of haematemesis. The endoscopic examination was repeated and there was a resistance at the upper third of oesophagus due to spasm of the oesophageal wall. Biopsies were taken. The patient suddenly collapsed and died on the next day.

Autopsy revealed a $750 \mathrm{ml}$ of clotted fresh blood in the thoracic cavity, which originated from a point between the oesophagus and the aorta. Further sectioning showed a perforation at the level of the arch of the aorta with a $3.5 \mathrm{~cm}$ long fish bone (Fig.1) impacted in the ulcerating aorto-oesophageal fistula (Fig. 2, Fig. 3). Tarry black stools were found in the lower gastrointestinal tract. 


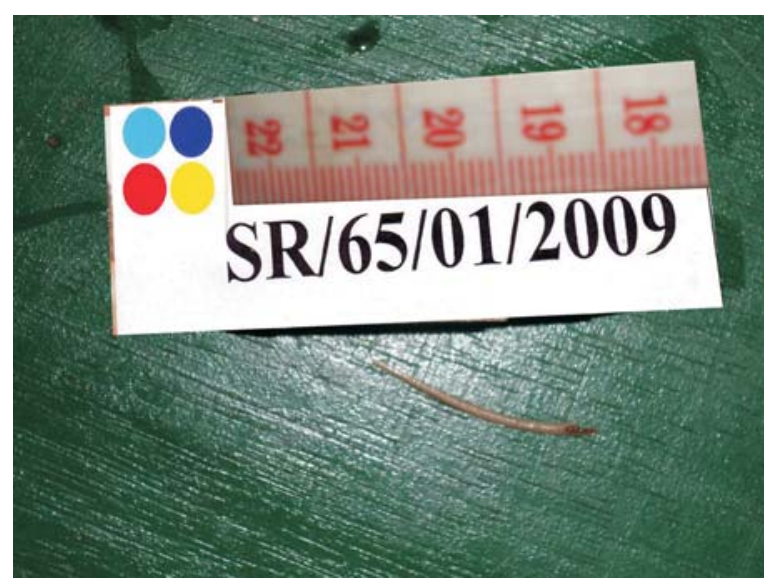

Figure 1: The fish bone removed from the fistula

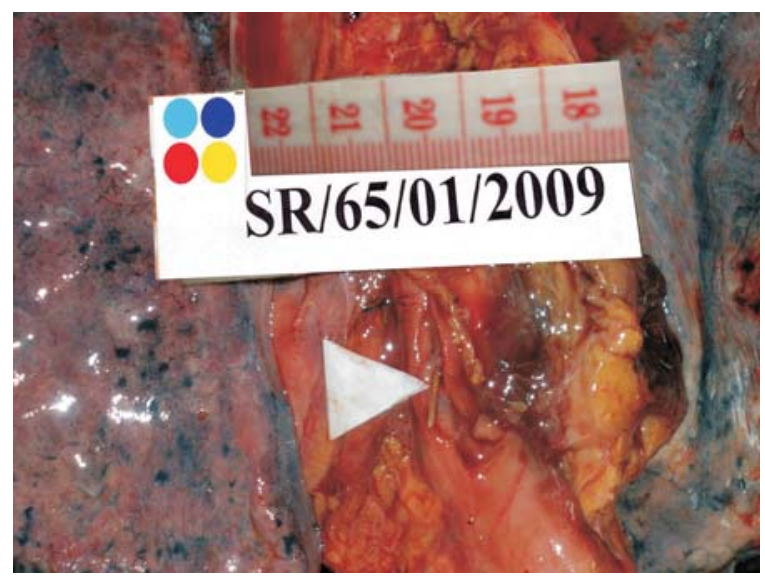

Figure 2: The ulcerating aorto-oesophageal fistula with the fish bone

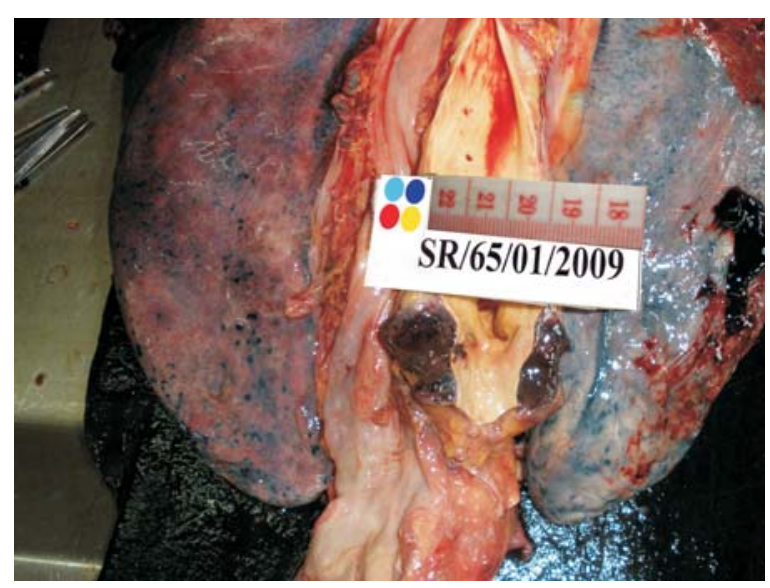

Figure 3: The aortic side of the fistula

\section{Discussion}

There are three main categories of patients where swallowed foreign bodies can be found. The commonest is the children between age of 18-48 months, which accounts for about $75 \%$ to $80 \%$ (2). Second group is psychiatric patients and prisoners where they can swallow bizarre objects including multiple objects. Third main group are the edentulous patients. Healthy adults get this very rarely. Sometimes, patient may be unaware, clinically atypical or ignorant of the impaction of the foreign body until serious complications are set in, as seen in this case (3).

There are three narrowings in the oesophagus which are important when foreign bodies are concerned. The upper oesophageal sphincter which consists of cricopharyngeal muscle is the narrowest part which is $1.5 \mathrm{~cm}$ in width. Secondly, the crossover of the aorta and the left main bronchus, and third place is the lower oesophageal sphincter. Because foreign bodies tend to get impacted at those places, these areas are more prone to get perforated from foreign bodies. Once the foreign body has passed through the oesophagus, there is more than $90 \%$ chance of it passing through the rest of the gastrointestinal tract.

Fish bone as a source of oesophageal foreign body is common in Asian community (4). The most common site of impaction is cervical oesophagus. The second commonest is at the level of the aortic arch (5). The clinical presentation of foreign body in the oesophagus greatly varies from acute pain and dysphagia to mere discomfort in swallowing depending on the type of foreign body and the place of impaction (6). The physical examination and plain radiography is of no help in many cases (7). The flexible oesophagoscopy, even though failed in the present case and carries a significant mortality and morbidity, and Computerized Tomography (8), remain the primary methods of diagnosis.

Vascular injuries causing aorto-oesophageal fistulae are considered to be one of the potentially lifethreatening complications. Typically, $45 \%$ patients present with chest pain, followed by haematemesis. The triad of mid thoracic pain, sentinel arterial haemorrhage and exsanguination after a symptom free interval has been termed 'Chiari's triad'. The aorto-oesophageal fistula is usually fatal in outcome (9). The surgical intervention by cross clamping of the thoracic aorta for arresting haemorrhage has been 
unsuccessful in many patients, and also carries a risk of paraplegia. However, many authors have stressed on importance of early consideration for surgical intervention when confronted with a brisk arterial bleed from the oesophagus with suggestive history of foreign body ingestion (10). The successful treatment requires the combination of surgical intervention with a hypothermic circulatory arrest.

\section{References}

1. Ishioka S, Safatle-Ribeiro A, Artifon EL, Sampaio Couto D Jr, Navarro A, Sakai P, Aun R, Utiyama E, Rasslan S, Birolini D. Artoesophageal fistula: successful management of hazardous complication caused by foreign body. Rev Gastroenterol Peru. 2008; 28: 278-81.

2. Boyle HW. Eosophageal Foreign Bodies: Intentional and Accidental. Swallowing news. 2004; 28(2).

3. Lossaco T, Lagiano R, Bera I, Santacroce L. An unusual foreign body in the upper aero-digestive tract: eosophageal obstruction due to bran impaction. European Review for Medical and Pharmacological Science. 2009; 13: 475-8.
4. Lim C.T, Quah R.F, Loh L.E. A prospective study of ingested foreign bodies in Singapore. Arch Otolaryngol Head Neck Surg 1994; 120: 96-101.

5. Sica GS, Djapardy V, Westaby S, Maynard ND. Diagnosis and management of aortoesophageal fistula caused by a foreign body. Ann Thorac Surg. 2004; 77: 2217-8.

6. Chiari H. Uber fremdkorperverletzung des oesophagus mit aortenperforation. Berl Klin Wschr 1914; 51: 7-9.

7. Wu IS, Ho TL, Chang CC, Lee HS, Chen MK. Value of lateral neck radiography for ingested foreign bodies using the likelihood ratio. J Otolaryngol Head Neck Surg. 2008; 37:292-6.

8. Das D. Is CT effective in cases of upper oesophageal fish bone ingestion? Emergency Medicine Journal 2007; 24: $48-2$.

9. D'Costa H, Bailey F, McGavigan B, George G, Todd B. Perforation of the oesophagus and aorta after eating fish: an unusual cause of chest pain. Emergency Medicine Journal 2003; 20: 385-2.

10. Lam EC, Brown JA, Whittaker JS. Esophageal foreign body causing direct aortic injury. Can J Gastroenterol. 2003 Feb; 17: 115-7. 